DOI: https://doi.org/10.47405/mjssh.v5i2.367

\begin{tabular}{|c|c|}
\hline 1. 1.54 & Malaysian Journal of Social Sciences and Humanities (MJSSH) \\
\hline $\begin{array}{c}\text { Malaysian Journal of } \\
\text { solal sciences and }\end{array}$ & Volume 5, Issue 2, February 2020 \\
\hline (MJ-SSH) & e-ISSN : 2504-8562 \\
\hline & $\begin{array}{l}\text { Journal home page: } \\
\text { www.msocialsciences.com }\end{array}$ \\
\hline
\end{tabular}

\title{
Amalan Gaya Komunikasi "Structuring" oleh Pengetua Wanita dalam Organisasi Pendidikan Menengah: Satu Kajian Kes
}

\author{
Emma Binti Tingkas' ${ }^{\text {, Syahruddin Awang Ahmad1 }}$ \\ 1Fakulti Kemanusiaan, Seni dan Warisan, Universiti Malaysia Sabah (UMS) \\ Correspondence: Emma Binti Tingkas (excel2u07@gmail.com)
}

\begin{abstract}
Abstrak
Salah satu ciri untuk menjadi pemimpin yang baik adalah dengan mengamalkan gaya komunikasi yang difikirkan sesuai berdasarkan persoalan tentang "siapa", "di mana" dan "bagaimana". Pengetua wanita merupakan golongan yang tidak terlepas daripada berhadapan dengan isu di tempat kerja melibatkan organisasi dan juga karenah warga didalamnya. Gaya komunikasi merupakan satu tool yang digunakan dalam memastikan kelancaran pentadbiran organisasi sekolah dan juga untuk menangani sebarang permasalahan yang timbul. Responden kajian terdiri daripada seorang pengetua wanita sebuah sekolah menengah yang terdapat dalam daerah Tuaran serta lebih kurang 40 orang guru yang bertugas di sekolah tersebut. Kaedah temubual mendalam dan tinjauan soal selidik telah dijalankan untuk mengenalpasti gaya komunikasi yang diamalkan oleh pengetua wanita terbabit. Konsep kajian adalah berteraskan kepada enam gaya komunikasi oleh Tubbs dan Moss dalam buku yang bertajuk Human Communication(2008). Hasil kajianmendapati pengetua wanita cenderung untuk mengamalkan gaya komunikasi yang dianggap paling dominan iaitu The Structuring Style. Kajian ini juga memberikan pemahaman yang lebih jelas tentang gaya komunikasi yang diamalkan oleh pengetua wanita dalam melaksanakan praktis pengurusan organisasi. Kajian ini diharapkan mampu untuk menjadi perintis agar satu kajian yang lebih mendalam berkaitan kepemimpinan pengetua wanita dari aspek komunikasi dapat dilakukan pada masa akan datang.
\end{abstract}

Kata kunci: gaya komunikasi, pengetua wanita, komunikasi dalam organisasi

\section{Structuring Communication Style by Female Principal in Secondary Education Organization}

\begin{abstract}
One of the characteristics of being a good leader is by practicing a communication style that is thought to be appropriate based on the question of Who, Where, How. Women principals are the ones who will not miss the work-related issues of the organization and their citizens. Communication style is a tool used to ensure the smooth running of the school organization as well as to address any issues that arise. The study respondents consisted of a female principal of a secondary school in Tuaran district and about 40 teachers of the school. In-depth Interview Methods and Survey Questions were conducted to identify the communication style practiced by the female principal. The concept of the study is based on six communication styles by Tubbs and Moss in a book entitled Human Communication (2008). The study found that female principaltends to adopt the most dominant communication style, The Structuring Style. This study also provides a clearer understanding of the communication style used by female principal in implementing organizational management practices. It is hoped that this study will
\end{abstract}


be able to pioneer a more in-depth study of female principal leadership in terms of communication in the future.

Keywords: communication style, female principal, communication in organization

\section{Pengenalan}

Tugas dan peranan yang perlu dilaksanakan oleh guru besar dan pengetua semakin mencabar dari sehari ke sehari kerana perkembangan pesat yang berlaku dalam sistem pendidikan, di dalam dan di luar negara (Abdullah Sani 2004; Ayob 2005; Cheng 2002; Goodlad 2004; Hussein 1997; Omardin 1997).

Pentadbiran sekolah di bawahpimpinan seorang pengetua telah menjadi suatu bidang yang memerlukan pengetahuan, kecekapan, pengalaman mengajar dan mentadbir yang tinggi. Pengetua sebagai pemimpin dan sekaligus sebagai pengurus pendidikan di sekolah adalah menjadi faktor utama kepada bukan sahaja kejayaan sebuah sekolah bahkan dengan kepimpinan dan pengurusannya dengan misi dan visinya boleh menentukan hala tuju institusi pendidikan yang diamanahkan kepadanya (Kertas Kerja Sistem Pendidikan Kebangsaan, 1998).

Pengetua merupakan pelaksana dasar pendidikan di peringkat sekolah dan menjadi orang nombor satu yang diletakkan harapan dalam memimpin sekolah yang diwakili untuk mendidik dan melahirkan anak bangsa yang berkualiti dari aspek akademik dan juga sahsiah.

"Principals can make a difference" demikian menurut Levin dan Lockheed (1993) manakala Ubben dan Hughes (1987) pula menyatakan "it is the leadership of the school that make the difference between mediocrity and excellence" membuktikan bahawa budaya kepimpinan pengetua yang ditonjolkan oleh pengetua itu sendiri merupakan faktor terpenting dalam memastikan kecemerlangan sesebuah sekolah untuk mencapai visi dan misi yang telah ditetapkan berlandaskan kepada Falsafah Pendidikan Kebangsaan iaitu melahirkan insan seimbang dari aspek jasmani, emosi, rohani dan intelektual.

\section{Komunikasi dan Sekolah}

Sekolah merupakan sebuah organisasi pendidikan yang diselenggarakan oleh golongan pendidik yang berinteraksi melalui suatu proses berstruktur untuk mencapai hasrat dan Falsafah Pendidikan Negara. Pendidikan dapat menghasilkan individu yang akan menikmati gaya hidup lebih selesa dan memuaskan. Ini hanya akan dapat diperoleh sekiranya sesebuah sekolah atau organisasi itu diuruskan dengan baik (Azizi Hj Yahya, et al, 2008).

Oleh yang sedemikian, adalah amat penting bagi sesebuah sekolah itu memiliki rangkaian komunikasi efektif antara golongan pendidik yang telah diletakkan dibahu mereka satu amanah agar generasi akan datang yang dilahirkan dari bimbingan serta didikan para warga pendidik ini tadi mampu untuk menjadi warganegara yang berguna kepada bangsa, agama dan negara.

Merujuk kepada kajian yang pernah dilakukan oleh Eisenberg pada tahun 1983 secara lazimnya terdapat tiga bentuk komunikasi yang biasanya diaplikasi di sekolah. Pertama; komunikasi ke bawah yang merujuk kepada arahan atau maklumat daripada Kementerian Pendidikankepada pejabat pendidikan dan sekolah melalui surat pekeliling, nota, surat atau minit mesyuarat. Kedua; komunikasi ke atas, melibatkan maklumat yang disampaikan oleh sekolah-sekolah kepada pejabat pelajaran, jabatan dan seterusnya ke kementerian. Ketiga; komunikasi mendatar yang memperlihatkan hubungan antara kakitangan melalui surat menyurat, mesyuarat, perhubungan sosial dan sebagainya. Pengaplikasian bentuk komunikasi ini memberikan peluang kepada semua kakitangan berbincang dan bertukar-tukar idea di samping mengeratkan hubungan silaturahim dalam kalangan mereka. 
DOI: https://doi.org/10.47405/mjssh.v5i2.367

\section{Penglibatan Wanita dalam Sektor Pendidikan}

Senario yang wujud dalam profesion perguruan di Malaysia masa kini adalah bilangan guru wanita dan pengetua wanita telah melebihi jumlah guru lelaki dan pengetua lelaki. Justeru, pemilihan pengetua tidak hanya berdasarkan jantina sebaliknya perlu berlandaskan kriteria seperti kemampuan, kekanan, pengalaman dan tahap keilmuan (Harvey dan Donaldson 2003).

Sebagai pengetua wanita di sesebuah sekolah selalunya menghadapi "dualisma"dalam bebanan tugas, iaitu sebagai pengetua di sekolah dan menghadapi tugas dan tanggungjawab mengurus rumah tangga. Keupayaan mereka menjalankan tugas kepimpinan di sekolah mungkin diragui oleh guru-guru bawahan, terutama guru-guru lelaki. Keraguan ini memberi kesan terhadap kepercayaan dan kerjasama yang diberikan. Di samping itu, pengetua wanita juga berhadapan dengan cabaran peribadi, iaitu harapan masyarakat terhadap pemimpin wanita yang sentiasa dikaitkan dengan sifat penyayang (Langer dan Boris-Schacter 2003).

\section{Gaya Komunikasi Pengetua Wanita Dalam Organisasi Pendidikan}

Gaya Komunikasi didefinisikan sebagai perilaku komunikasi yang digunakan untuk mendapatkan respon atau tanggapan tertentu dalam situasi yang berbeza. Kesesuaian dari gaya komunikasi yang digunakan bergantung kepada tujuan atau maksud daripada pengirim (sender) dan harapan daripada penerima (receiver) (Herwan Parwiyanto, 2009).

Norton (1975) menyatakan "communication styles as the way a person uses verbal and nonverbal communicative behaviours to indicate how literally others should interpret a message". Penggunaan gaya komunikasi yang bersesuaian akan membantu golongan penerima mesej dalam mentafsir mesej tersebut dan bagaimanakah respon yang sepatutnya diberikan.

Dalam kajian yang dilakukan oleh Norhannan dan Jamaliah (2006) menyatakan pengetua wanita cenderung untuk memberikan penekanan terhadap disiplin para guru berdasarkan kepada dapatan kajian yang diperolehi. Gaya kepimpinan yang berorientasikan struktur tugas merupakan gaya kepimpinan yang lebih dominan diamalkan. Berdasarkan kajian yang dilakukan oleh mereka adalah didapati prestasi pengetua wanita berada dalam tahap memuaskan dan pengetua wanita memberikan penekanan terhadap prestasi kerja serta kurang menekankan aspek motivasi terhadap para subordinat mereka.

Oleh yang demikian berdasarkan dapatan kajian tadi maka adalah didapati pengetua wanita lebih menjurus kepada pengaplikasian gaya komunikasi berbentuk "Structuring". Gaya komunikasi ini memberikan penekanan terhadap usaha untuk memastikan setiap guru yang berperanan sebagai subordinat mematuhi peraturan sedia ada dalam melaksanakan tanggungjawab yang diamanahkan kepada mereka. Dalam erti kata lain, pengetua wanita amat menitikberatkan perihal dsiplin kalangan guru yang berkhidmat dibawah beliau.

Kajian lepas seterusnya yang telah dilakukan oleh Hassan dan Normala pada tahun 2008 memberikan maklumat terbaru berkaitan kemampuan seorang guru wanita dalam melaksanakan tanggungjawab sebagai seorang pemimpin di sekolah. Pengetua wanita dapat mengimplementasi polisi sedia ada dan melakukan perancangan dalam usaha untuk melakukan perubahan di sekolah supaya menjadi lebih efektif. Naluri keibuan yang ada pada pengetua wanita memudahkan golongan terbabit memainkan peranan sebagai penasihat dan memberikan galakan, kata-kata motivasi kepada guru-guru dibawah mereka. Amalan kepimpinan yang ditonjolkan juga lebih menjurus kepada gaya komunikasi "Structuring" iaitu menjalankan peranan berlandaskan kepada SOP (Standard of Procedure) sedia ada serta menggunakan sepenuhnya mesyuarat mingguan sebagai contoh untuk menyampaikan saranan kepada golongan subordinat melibatkan visi dan misi organisasi yang perlu untuk dicapai. Individu yang mengaplikasikan gaya komunikasi ini juga menggunakan sepenuhnya "tool" komunikasi secara lisan dan bukan lisan dalam berinteraksi dengan golongan subordinat. 


\section{Pernyataan Masalah}

Kegagalan komunikasi ini berlaku akibat beberapa faktor antaranyakurangnya kekerapan berkomunikasi, ada jurang komunikasi, menggunakan komunikasi sehala, cara gaya komunikasi yang tidak baik, bentuk komunikasi yang tidak berkesan dan adanya halangan-halangan komunikasi menurut kajian yang dilakukan oleh Abdul Halim (1994). Malahan menurut Kamaruddin (1989) kegagalan komunikasi atau kurangnya berkomunikasi boleh menyebabkan syak wasangka, salah anggap atau curiga dalam kalangan guru, pelajar dan kakitangan sekolah yang seterusnya akan mendatangkan kesan terhadap perjalanan pengurusan serta pentadbiran sekolah.

Oleh yang demikian kajian ini memfokuskan kepada persoalan berkaitan jenis gaya komunikasi yang diamalkan oleh pengetua wanita terbabit dalam menjalankan amanah iaitu memimpin, mengurus serta mentadbir perjalanan sekolah menuju kearah kecemerlangan berteraskan kepada Falsafah Pendidikan Kebangsaan serta meninjau persepsi kalangan subordinat terhadap pengaplikasian gaya komunikasi yang diamalkan.

\section{Objektif Kajian}

Kajian ini bertujuan untuk mengenalpasti gaya komunikasi yang diamalkan oleh pengetua wanita dalam melaksanakan tanggungjawab sebagai ketua dalam organisasi. Berdasarkan permasalahan kajian yang telah dinyatakan tadi, objektif kajian ini adalah seperti berikut:-

i. Untuk mengenalpasti gaya komunikasi yang diaplikasikan oleh pengetua wanita

ii. Untuk meninjau persepsi subordinat terhadap gaya komunikasi pengetua wanita mereka.

\section{Kepentingan Kajian}

Matlamat kajian ini adalah untuk mengenalpasti bentuk gaya komunikasi yang diamalkan oleh Pengetua Wanita, meninjau persepsi kalangan subordinat terhadap Pengetua Wanita dalam memimpin dan mentadbir sekolah.Selain daripada itu, kajian ini juga adalah selaras dengan resolusi yang terdapat dalam Kementerian Pembangunan Wanita, Keluarga dan Masyarakat yang mahu satu kajian khusus dilakukan mengenai penglibatan wanita di peringkat membuat keputusan untuk mengenalpasti sebarang halangan yang dihadapi kaum wanita serta mengadakan penyelesaian terbaik untuk halangan tersebut.

\section{Kerangka Konseptual}

Kerangka konsep dalam Rajah 1 menunjukkan pengetua wanita dalam organisasi pendidikan menengah di sebuah sekolah menengah yang terletak dalam daerah Tuaran yang menjadi informan utama dalam kajian ini. Terdapat dua komponen utama yang menjadi fokus dalam kajian ini iaitu yang pertama mengenalpasti gaya komunikasi yang diamalkan oleh pengetua wanita dalam menjalankan peranan sebagai ketua organisasi. Gaya komunikasi yang diaplikasi oleh pengetua wanita dalam menjadi seorang ketua organisasi akan mampu memberikan gambaran kepada subordinat tentang perilaku pengetua wanita mereka.

Komponen kedua yang menjadi fokus dalam kajian ini adalah untuk meninjau persepsi kalangan subordinat tentang gaya komunikasi yang diamalkan oleh pengetua wanita dan ini akan memberikan gambaran sejauh mana kalangan subordinat ini menerima pengetua wanita sebagai ketua dalam organisasi berdasarkan kepada pengaplikasian gaya komunikasi yang digunakan oleh pengetua wanita dalam mengurus dan memimpin sekolah. 


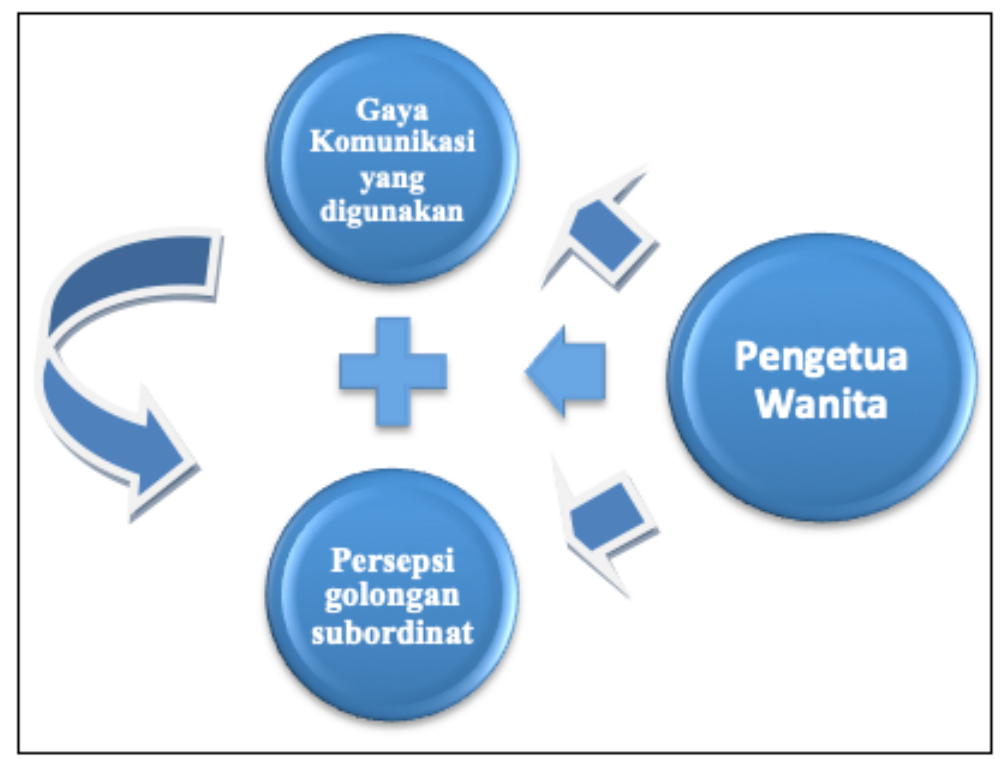

Rajah 1: Kerangka Konseptual

\section{Metod Kajian}

Kajian yang dijalankan ini merupakan penyelidikan berbentuk kualitatif dan juga kuantitatif iaitu kajian yang menggunakan kaedah gabungan ataupun disebut sebagai "mix method"dalam usaha untuk mengumpul data kajian seterusnya untuk mencapai objektif serta menjawab persoalan dalam kajian ini.

Penyelidikan berbentuk kualitatif merupakan kajian yang mementingkan elemen makna, pemahaman yang teliti dan realiti sebenar mengenai situasi yang dikaji. Antara komponen yang tergolong dalam perspektif kualitatif ini adalah naturalistic, field study, case study, context, situational, constructivism, meaning or multiple realities.

Pendekatan kualitatif berasaskan 'kualiti', ianya bersifat deskriptif yang lebih kepada penghuraian "makna" perkara-perkara yang dikaji. Pendekatan kualitatif tidak mengutamakan data-data berbentuk numerikal. Skop kajiannya meliputi bilangan responden yang kecil jika dibandingkan dengan skop kajian berbentuk kuantitatif. Kajian ini dijalankan dengan menggunakan temubual mendalam, pemerhatian dan analisis dari dokumen-dokumen yang berkaitan dengan kajian.

Selain daripada itu, pengkaji juga menggunakan kaedah kuantitatif dalam mendapatkan respon yang jelas berkaitan gaya komunikasi Pengetua Wanita berdasarkan tinjauansoal selidik dalam kalangan subordinat sekolah terbabit. Pengkaji menggunakan instrumen soal selidik berdasarkan instrumen kajian yang telah dijalankan oleh Al Muz Zammil dan Azmi dari Fakulti Pendidikan, Universiti Teknologi Malaysia pada tahun 2011.

Penyelidikan berbentuk kuantitatif mempunyai ciri-ciri keupayaan digeneralisasi yang tinggi (Chua, 2006). Melalui kaedah ini, borang soal selidik digunakan untuk mengumpul data bagi memperolehi dapatan kajian sekaligus untuk menyokong dapatan kajian daripada data kualitatif. Pemilihan responden adalah berdasarkan sampel rawak mudah supaya setiap guru yang berperanan sebagai golongan subordinat mempunyai peluang yang sama untuk terlibat dalam kajian.

Data yang diperolehi daripada borang soal selidik dikumpul dan kemudian dianalisis untuk mengenalpasti persepsi kalangan subordinat berkenaan tentang gaya komunikasi yang diamalkan oleh pengetua wanita. Dapatan analisis dipersembahkan dalam bentuk jadual menggunakan statistik deskriptif iaitu peratus dan juga min. Analisis menggunakan peratus dan min ini digunakan oleh pengkaji untuk melihat tahap gaya komunikasi pengetua wanita dari sudut perspektif golongan 
DOI: https://doi.org/10.47405/mjssh.v5i2.367

subordinat. Tahap gaya komunikasi akan dikategorikan kepada tiga peringkat iaitu: Rendah, Sederhana dan Tinggi seperti jadual yang ditunjukkan berdasarkan sumber Wiersma William, 1995.

Jadual 1 Julat Skala Gaya Komunikasi Berdasarkan Skor Min

\begin{tabular}{ll}
\hline Skor Min & Tahap Gaya Komunikasi \\
\hline $1.00-2.40$ & Rendah \\
$2.41-3.80$ & Sederhana \\
$3.81-5.00$ & Tinggi \\
\hline
\end{tabular}

\section{Dapatan Kajian}

\section{"The Structuring Style"}

Berdasarkan sesi Temuramah Mendalam yang telah dijalankan bersama dengan pengetua wanita yang berkhidmat di sebuah sekolah menengah luar bandar yang terletak dalam daerah Tuaran adalah didapati Gaya Komunikasi “Structuring” atau juga disebut sebagai “The Structuring Style” merupakan gaya komunikasi yang paling dominan.

Dapatan kajian ini juga disokong menerusi analisis data kuantitatif daripada Tinjauan Soal Selidik apabila gaya komunikasi "Structuring" mencatatkan min tertinggi iaitu 4.20 dari enam jenis gaya komunikasi menurut Tubbs dan Moss (2008) iaitu: Gaya Komunikasi "Dynamic", Gaya Komunikasi "Equalitarian", Gaya Komunikasi "Controlling", Gaya Komunikasi "Structuring", Gaya Komunikasi "Relinquish" dan Gaya Komunikasi "Withdrawal".

Jadual 2: Peratus dan Min bagi item Gaya Komunikasi Penstrukturan

\begin{tabular}{|c|c|c|c|c|c|c|c|}
\hline $\begin{array}{l}\text { Item Soalan } \\
\text { Min Gaya } \\
\end{array}$ & $\begin{array}{l}\text { Gaya Komunikasi } \\
\text { Penstrukturan }\end{array}$ & $\begin{array}{l}\text { TP } \\
\% \\
\end{array}$ & $\begin{array}{l}\text { JJ } \\
\% \\
\end{array}$ & $\begin{array}{l}\text { SS } \\
\%\end{array}$ & $\begin{array}{l}\text { KK } \\
\% \\
\end{array}$ & $\begin{array}{l}\mathrm{S} \\
\%\end{array}$ & \\
\hline 13 & $\begin{array}{l}\text { Pengetua mengikut } \\
\text { arahan jabatan dalam } \\
\text { membuat keputusan }\end{array}$ & - & 10.0 & 15.0 & 32.5 & 42.5 & 4.08 \\
\hline 14 & $\begin{array}{l}\text { Pengetua mempengaruhi } \\
\text { guru-guru untuk mematuhi } \\
\text { peraturan sedia ada }\end{array}$ & 2.5 & 2.5 & 15.0 & 20.0 & 60.0 & 4.32 \\
\hline 15 & $\begin{array}{l}\text { Pengetua menggunakan - } \\
\text { kedudukan untuk persetujuan } \\
\text { guru-guru }\end{array}$ & 10.0 & 7.5 & 25.0 & 57.5 & 4.30 & \\
\hline 16 & $\begin{array}{l}\text { Pengetua melaksanakan } \\
\text { arahan tanpa mengambil } \\
\text { kira perasaan guru }\end{array}$ & 7.5 & 5.0 & 7.5 & 30.0 & 50.0 & 4.10 \\
\hline Keseluruhan & Tinggi & & & & & & $* 4.20 *$ \\
\hline
\end{tabular}

Menurut Tubbs dan Moss (2008) dalam buku mereka berjudul Human Communication menyatakan gaya komunikasi "Structuring" ini merujuk kepada seseorang yang memanfaatkan mesej-mesej secara bertulis mahupun lisan diguna untuk memantapkan arahan yang harus dilaksanakan,penjadualan tugas dan pekerjaan serta struktur organisasi. Pengirim mesej (sender) lebih memberikan perhatian kepada 
keinginan untuk mempengaruhi orang lain dengan cara menyampaikan informasi tentang tujuan organisasi, jadual kerja, peraturan dan prosedur yang berlaku dalam organisasi tersebut.

Sepanjang sesi temubual mendalam berlangsung, pengetua wanita yang menjadi informan utama dalam kajian ini secara konsisten memberikan penekanan terhadap kepentingan profesionalisma diamalkan dalam melaksanakan tanggungjawab sebagai warga pendidik serta sebagai seorang ketua organisasi. Standard amalan profesionalisma sebagai seorang pengetua perlulah dijadikan sebagai panduan melaksanakan tanggungjawab sebagai pemimpin nombor satu di sekolah seperti mana yang terkandung menurut Standard Kompetensi Kepengetuaan Sekolah Malaysia (SKKSM) yang diperkenalkan dalam Pelan Pembangunan Pendidikan Malaysia (PPPM) 2013-2025.

Pengetua wanita ini berulang kali menyatakan kepentingan untuk beliau berkongsi visi dan misi dengan para subordinat dalam memastikan kecemerlangan sekolah mampu direalisasikan. Pernyataan beliau berkaitan peranan komunikasi dalam organisasi dapat dilihat secara jelas berdasarkan petikan temubual berikut:-

Informan: The leaders should communicate dia punya vision...kalau ikut betulbetul tu Emma it sounds so easy. You should study your organization... setelah study ... you make your strategic planning... in 3 years or 5 years saya mesti begini...the school will transform from this situation to another situation...Kita kasi tahu the whole thing, make it know to everyone and then PK School, 3 unit itu bekerja, buat dorang punya planning...satu you communicate your vision and then the most difficult thing juga... how can I explain...satu you must have your vision, satu lagi you must have your HR...your HR itu you must train...jadi through the training juga merupakan bentuk communication...so through training jugalah the real process...you train them and Emma this is the leading process...the leading process ini is to training them...dalam pengertian yang sebenar what is leading is to showing people how to do it...

Gaya komunikasi "Structuring" ini memberikan penekanan terhadap mengguna pakai prosedur sedia ada dalam menjalankan pengurusan dan pentadbiran organisasi. Pengetua wanita yang menjadi informan utama dalam kajian ini merupakan seorang pengurus dan pentadbir sekolah yang menggunakan ruang seperti mesyuarat harian dengan para subordinat untuk secara berterusan menyampaikan visi dan misi organisasi yang harus dicapai.

Perkataan "vision" yang kerap kali digunakan sepanjang sesi temuramah berlangsung memberikan satu persepsi berkaitan ciri kepimpinan yang ditunjukkan oleh pengetua wanita dalam mengurus dan mentadbir sekolah. Pengetua wanita juga memberikan penekanan terhadap setiap urusan yang melibatkan pengurusan serta pentadbiran perlulah berlandaskan kepada SOP (Standard of Procedure) yang perlu dipatuhi. Pengetua wanita turut menekankan betapa penting untuk beliau melaksanakan perancangan melibatkan pembaharuan di sekolah kerana matlamat utama adalah bagi merealisasikan visi dan misi seterusnya mencapai KPI (Key Performance Indicator) seperti yang dikehendaki oleh pihak kementerian mahupun pihak jabatan.

\section{Perbincangan}

Analisis kajian yang diperolehi merumuskan bahawa informan utama dalam kajian ini iaitu Pengetua Wanita mengamalkan gaya komunikasi "Structuring"yang memberikan penekanan terhadap penggunaan "verbal" dan "non verbal" (lisan dan bertulis) untuk memberikan arahan yang perlu diambil perhatian serta tindakan susulan dari kalangan subordinat.

Dapatan kajian dari data kualitatif ini juga turut disokong dengan dapatan kajian dari data kuantitatif menerusi tinjauan soal selidik yang telah dijalankan keatas subordinat. Kalangan subordinat bersetuju bahawa Pengetua Wanita merupakan ketua organisasi yang mengaplikasikan gaya komunikasi "Structuring" dalam melaksanakan peranan sebagai individu yang diberikan amanah untuk menjadi 'orang nombor satu' di sekolah. Gaya komunikasi jenis "Structuring” mencatatkan min tertinggi iaitu 
4.20 dari 6 jenis gaya komunikasi menurut Tubbs dan Moss berdasarkan analisis borang soal selidik yang diedarkan kepada golongan subordinat.

Kalangan subordinat turut bersetuju bahawa pengetua wanita mempengaruhi para guru untuk mematuhi peraturan sedia ada dan sudah seharusnya pengetua wanita membuat keputusan yang dirasakan selaras dengan etika perguruan demi menjaga profesionalisma sebagai warga pendidik dalam mendidik anak bangsa. Elemen mempengaruhi golongan subordinat untuk mematuhi peraturan yang telah ditetapkan merupakan antara ciri yang mewakili gaya komunikasi "Structuring" selain daripada menggunakan sepenuhnya komunikasi lisan dan bukan lisan sebagai medium interaksi terutama sekali ketika pengetua wanita perlu untuk menjalankan peranan formal sebagai ketua organisasi.

Seperti yang telah dinyatakan dalam analisis awal bagi data kualitatif, pengkaji mendapati pengetua wanita inisangat mementingkan profesionalisma dalammenjalankan tugas. Pengetua wanita juga merupakan seorang pemimpin yang menekankan elemen disiplin untuk memastikan setiap arahan yang disampaikan oleh beliau kepada pihak bawahan harus dilaksanakan dengan sebaik mungkin mengikut SOP (Standard of Procedure) sedia ada yang telah dietapkan oleh pihak kementerian pelajaran.

Pengetua wanita juga merupakan kakitangan awamdanwarga pendidik yang turut menerima arahan daripada PPD (Pejabat Pendidikan Daerah), Jabatan Pendidikan Negeridan juga pihak Kementerian Pendidikandalam memastikan sekolah menengah yang diterajui beliau mampu untuk bersaing dan mencapai matlamat seterusnya melahirkan golongan pelajar yang bersahsiah serta berprestasi tinggi dalam bidang akademik dan juga kokurikulum.

Kalangan subordinat berpendapat pengetua wanita juga menggunakan kedudukan untuk mendapatkan persetujuan guru dalam memastikan setiap arahan yang disampaikan akan disusuli dengan tindakan segera. Greenfield (1995) berpendapat bahawa sekolah adalah berbeza daripada organisasi yang lain. Hal ini dapat dilihat dari segi usaha-usaha moralnya kerana pengurusan sekolah secara uniknya melibatkan komunikasi bersemuka secara ekstensif, berorientasikan aksi, reaktif, masalah di luar jangkaan, keputusan dibuat secara segera serta menghadapi tekanan yang berterusan untuk mempertahankan perjalanan sekolah yang lancar dan aman (Blumberg, 1989).

Dapatan kajian ini turut disokong oleh Ahmad Safwan (2007); Hazman (2008) dan Bashid (2008) dalam kajian yang dilakukan sebelum ini dan mereka mengemukakan beberapa taktik yang boleh digunakan untuk mempengaruhi orang lain dalam organisasi oleh pemimpin dan sekiranya pemimpin itu menggunakan kedudukan, peraturan dan tradisi organisasi untuk mempengaruhi orang bawahan melaksanakan tugas, itu bermakna pemimpin tersebut menggunakan taktik yang sah. Strategi ini berkesan sekiranya pemimpin tersebut mempunyai autoriti formal

Oleh yang demikian, pengetua wanita harus bijak menggunakan kedudukan beliau sebagai pengurus dan pemimpin utama di sekolah bukan sahaja dalam memberikan arahan namun juga ketika perlu untuk membuat keputusan penting melibatkan sekolah yang diterajui oleh beliau. Semangat profesionalisma merupakan elemen yang seharusnya dijadikan sebagai budaya dalam bekerja secara berpasukan yang mana pengetua wanita merupakan orang yang bertanggungjawab untuk mencorakkan suasana persekitaran yang kondusif agar kalangan subordinat boleh menjalankan peranan masingmasing dengan efektif.

Sebarang keputusan yang diambil haruslah dibuat secara bersama dan pengetua wanita perlu menggunakan peluang sewaktu berinteraksi dengan subordinat terutamanya dalam mesyuarat mingguan untuk menyampaikan saranan dan mendapatkan sokongan serta persetujuan dari orang bawahan beliaubagi memastikan keefektifan komunikasi tersebut diterjemahkan dalam bentuk tindakan.

Pengetua wanita juga dikatakan melaksanakan arahan tanpa mengambil kira perasaan guru berdasarkan analisis data kuantitatif yang diperolehi dari kalangan subordinat. Pengetua wanita harus mempunyai sikap yang tegas biarpun terdapat persepsi yang beranggapan pengetua wanita tidak mengambil peduli perasaan orang bawahan namun sekiranya tindakan yang diambil tersebut mampu membawa anjakan 
paradigma dalam pencapaian prestasi sekolah maka ia merupakan satu tindakan yang perlu dilihat dari sudut positif.

Namun pengetua wanita seharusnya juga perlu melihat dari skop yang lebih luas ketika menggunakan autoriti yang berada ditangan beliau kerana sebagai seorang pemimpin, beliau mempunyai tanggungjawab besar dalam mencorakkan perjalanan pentadbiran sekolah sebagai satu organisasi yang pragmatik. Pengetua wanita perlu juga mempunyai sikap "empati" terhadap kalangan subordinat namun pada masa yang sama masih mengekalkan elemen sifat ketegasan dan berintegriti dalam memimpin sekolah. Perkara ini disokong dengan kenyataan oleh (Mortimore, 1995) yang menyatakan salah satu faktor sekolah berkesan ialah pengetua yang mempunyai kepimpinan professional iaitu pengetua yang mempunyai sikap yang tegas serta bermatlmat.

Keberkesanan pentadbiran dan pengurusan sekolah seharusnya juga tidak mengabaikan elemen kebersamaan antara pihak pengetua sebagai pihak atasan serta golongan subordinat terutama sekali apabila sebarang tindakan yang diambil atau program yang dirancang melibatkan kepentingan para pelajarnya. Oleh yang demikian sikap keterbukaan turut menjadi elemen penting dalam meneruskan perancangan yang telah dilakukan untuk mencapai visi dan misi yang telah ditetapkan sebelum itu.

Kecemerlangan sesebuah sekolah berkait rapat dengan penglibatan secara aktif kepimpinan menerusi pengetua dan juga perkembangan yang ditunjukkan oleh para pelajarnya menurut Oboegbulem (2013). Fullan (1982) pula menyatakan pengetua adalah orang yang paling penting dalam membuat perubahan di sekolah. Pengetua boleh dianggap sebagai individu yang berperanan sebagai perintis utama dalam melaksanakan pembaharuan dan perubahan yang diperlukan terutama sekali dalammeningkatkan prestasi sekolah dari aspek akademik dan juga kokurikulum.

Kepatuhan pengetua wanita terhadap arahan yang diberikan oleh pihak jabatan dapat diterjemahkan berdasarkan pandangan yang diberikan oleh kalangan subordinat dalam kajian ini. Pengetua wanita dikatakan mengikut arahan pihak jabatan dalam membuat keputusan dan ini telah menguatkan lagi fakta bahawa pengetua wanita merupakan pemimpin dan pengurus yang sangat mengambil kira elemen kepatuhan terhadap standard kepengetuaan yang telah ditetapkan.

Gaya komunikasi "Structuring" merupakan satu gaya komunikasi yang memfokuskan sebarang bentuk arahan perlu dilaksanakan oleh kalangan subordinat, pengetua wanita memberikan arahan bertujuan untuk memperbaiki prestasi serta mencapai visi dan misi sekolah berteraskan kepada Falsafah Pendidikan Kebangsaan untuk melahirkan pelajar minda kelas pertama. Hal ini dapat dibuktikan menurut Lunenburg (2010) dalam kajian beliau iaitu "The Principal and the School: What do Principals do?" yang menyatakan:

Once all the formal plans are formulated and activities are organized, the leading of staff members to achieve the school's goals is an important action that must taken by the leader". "Leading as argued, guides and influences people, and is a means of communicating goals to staff members" (Lunenberg, 2010).

Pernyataan ini secara jelas memperlihatkan elemen gaya komunikasi "Structuring"dan signifikan dengan data yang diperolehi berdasarkan kaedah kualitatif dan kuantitatif dalam kajian ini sekaligus menyokong dapatan kajian yang dilakukan oleh Lunenberg (2010).

Maka oleh sebab itu, tidak menghairankan jika gaya komunikasi "Structuring" merupakan gaya komunikasi yang seringkali menjadi gaya komunikasi dominan yang diamalkan oleh para pemimpin organisasi mahupun sebagai ketua sebuah kerajaan. Sebagai contohnya berdasarkan kajian yang pernah dijalankan oleh Riswandi dari Universiti Mercu Buana Jakarta pada tahun 2017, pengkaji memfokuskan kajian dengan mengambil situasi menjelang pemilihan presiden Indonesia dalam pilihanraya 2014. Kajian tersebut dilaksanakan bertujuan untuk mengenalpasti gaya komunikasi yang diamalkan oleh calon Presiden ketika itu iaitu Joko Widodo (kemudiannya dikenali sebagai Presiden Jokowi) dan saingannya ketika itu Prabowo Subianto. 
Menariknya hasil dapatan kajian oleh pengkaji tersebut mendapati kedua-dua calon presiden Indonesia pada tahun itu memperlihatkan ciri gaya komunikasi "Structuring" atau juga disebut sebagai "The Sturucturing Style"dalam siri kempen calon presiden semasa Pilihanraya Indonesia bermula pada awal bulan Jun 2014 dan berakhir pada bulan Julai 2014. Kedua-dua calon Presiden ketika itu menggunakan sepenuhnya medan kempen pilihanraya untuk menyampaikan mesej kepada para pengundi akan hala tuju perancangan untuk membawa Indonesia maju ke hadapan sekiranya terpilih sebagai Presiden negara republik yang memiliki antara penduduk paling ramai di dunia.

Mantan Perdana Menteri Wanita pertama Britain iaitu mendiang Margaret Thatcher juga merupakan seorang pemimpin yang mengamalkan gaya komunikasi "Structuring" dalam memimpin Britain keluar dari zaman kegawatan ekonomi ketika era 80an. Gaya komunikasi ini yang memfokuskan penekanan terhadap memberikan arahan dan harus disusuli dengan tindakan merupakan "tool" yang berkesan dalam melaksanakan pengurusan serta pentadbiran kerajaan pimpinan beliau sehingga beliau digelar The Iron Lady. Karismamendiang Margaret Thatcher sebagai Perdana Menteri Pertama Wanita Britain yang sememangnya terkenal dengan ketegasan beliau merupakan antara kunci kepada kemampuan "Wanita Besi" ini untuk bertahan selama lebih 10 tahun sebagai Perdana Menteri. Beliau juga memegang rekod sebagai Perdana Menteri yang paling lama berkhidmat selepas era Winston Churchill.

Dalam satu artikel yang ditulis oleh Haziq Khairin (2018) yang diterbitkan untuk www.thepatriots.asia memuatkan fakta berkaitan usaha Margaret Thatcher dalam menggerakkan pelan penstrukturan semula ekonomi Britain yang terjejas teruk ekoran kegawatan ekonomi yang dihadapi oleh kebanyakan negara di dunia pada era 80an. Beliau telah melancarkan dasar pembaharuan pada tahun 1981 berkaitan dengan polisi kewangan serta mengumumkan belanjawan tahunan yang ketat menyaksikan banyak peruntukan kerajaan dikurangkan seterusnya menyebabkan kadar pengangguran di Britain meningkat. Kadar pengangguran yang meningkat dalam kalangan rakyat Britain menjadikan beliau bukanlah Perdana Menteri yang popular pada waktu itu. Namun demikian langkah yang diambil oleh kerajaan pimpinan Margaret Thatcher adalah bertujuan untuk menyelamatkan Britain daripada risiko menjadi negara muflis. Pada akhirnya mendiang Margaret Thatcher akan sentiasa dikenang sebagai antara ikon politik wanita yang unggul serta merupakan antara bekas Perdana Menteri Britain yang paling popular selepas Sir Winston Churchill. Setakat pada hari ini belum terdapat pemimpin politik wanita dunia yang mampu mengatasi pencapaian mendiang Margaret Thatcher.

Oleh yang demikian, terdapat persamaan gaya komunikasi yang diaplikasi menerusi amalan budaya kepimpinan yang ditonjolkan oleh pengetua wanita, mantan Perdana Menteri Britain iaitu mendiang Margaret Thatcher dan juga Presiden Indonesia iaitu Presiden Jokowi dalam usaha para pemimpin ini melaksanakan segala usaha tranformasi yang dirasakan perlu demi mencapai sasaran yang ditetapkan.

Pengetua wanita yang menjadi unit analisis dalam kajian ini berjaya membawa kepada perubahan dan peningkatan yang membanggakan dan antara pencapaian tersebut adalah sekolah menengah yang diterajui beliau berjaya mendapat Anugerah Lonjakan Terbaik (peringkat negeri Sabah) dalam peperiksaan SPM untuk tahun 2017 seperti yang diumumkan pada tahun 2018.

Ikon pemimpin dunia seperti mendiang Margaret Thatcher berjaya mengubah persepsi masyarakat terutamanya kalangan rakyat Britain sendiri serta menghapuskan stigma berkaitan keupayaan kaum wanita untuk berperanan sebagai ketua kerajaan. Presiden Jokowi pula berjaya membawa republik Indonesia terus berkembang pesat dan makmur dari aspek ekonomi. Kejayaan Presiden Jokowi untuk kekal sebagai Presiden Indonesia bagi penggal ke-2 selepas pilihanraya pemilihan Presiden pada tahun 2019 merupakan bukti betapa rakyat Indonesia menyakini kewibawaan yang dimiliki oleh Presiden Jokowi.

Berdasarkan analisis yang telah dilakukan dapatlah dirumuskan bahawa, kalangan subordinat berpendapat pengetua wanita lebih menitikberatkan aspek setiap arahan yang diberikan sewajarnya dipatuhi oleh mereka dan dilaksanakan dengan sebaik mungkin. Sebagai ketua organisasi yang diberikan kepercayaan dalam menerajui sebuah sekolah menengah luar bandar, pengetua wanita 
menggunakan kedudukan serta pengaruh yang ada pada beliau untuk memastikan matlamat organisasi mampu dicapai.

Gaya komunikasi yang bersesuaian perlulah digunakan agar satu pasukan yang mantap dapat dibentuk demi memastikan prestasi sekolah mampu dipertingkatkan seterusnya melahirkan pelajar minda kelas pertama dan generasi muda inilah yang akan meneruskan kesinambungan kepemimpinan negara pada masa hadapan. Pengaplikasian gaya komunikasi oleh individu yang berperanan sebagai ketua tidak terhad kepada satu bentuk gaya komunikasi sahaja. Dalam kebanyakan situasi, seorang pemimpin yang berkesan akan mengaplikasikan gaya komunikasi tertentu mengikut kesesuaian persekitaran serta kelompok subordinat yang menerima arahan ataupun berinteraksi dengan pihak atasan.

\section{Kesimpulan}

Dapatan kajian telah dapat membantu penyelidik untuk mengenalpasti gaya komunikasi yang paling dominan diaplikasi oleh pengetua wanita iaitu gaya komunikasi "Structuring". Gaya komunikasi yang diamalkan adalah signifikan terhadap keperluan berdasarkan tempat dan kelompok subordinat yang menerima arahan secara terus dari pengetua wanita. Dapatan kajian ini juga menyokong dapatan kajian yang diperolehi dalam kajian terdahulu yang dibuat oleh kalangan sarjana.

"You can'tplease everyone" merupakan satu "quote" yang membawa maksud kita tidak boleh memuaskan hati semua pihak. Sebagai seorang ketua, sebarang persepsi yang datangnya daripada kalangan subordinat samaada persepsi tersebut berbentuk positif atau negatif, ia seharusnya tidak dijadikan sebagai satuisu besar sehingga membelakangkan matlamat yang lebih utama untuk dicapai. Disiplin dan ketegasan merupakan dua kunci utama yang dapat dikaitkan dengan gaya komunikasi "Structuring" ini dan adalah diharapkan kajian ini boleh membuka peluang kepada satu kajian yang lebih menyeluruh melibatkan peranan pengetua wanita dapat dilakukan pada masa akan datang. Memetik kata-kata Eleanor Roosevelt, isteri kepada bekas presiden Amerika Syarikat iaitu Presiden Roosevelt, beliau pernah berkata:

\section{"Woman is like a tea bag, you never know how strong she is until she gets into hot water"}

Oleh yang demikian, peranan pengetua wanita sebagai ketua dalam organisasi di sekolah merupakan satu sumbangan yang mampu membawa kepada tranformasi sekolah berkenaan dalam meningkatkan prestasi terutama sekali dari aspek akademik dan kokurikulum. Kewibawaan yang ditonjolkan oleh pengetua wanita adalah setanding dengan pengetua lelaki dan pengetua wanita yang menjadi informan utama dalam kajian ini telah berjaya membuktikan kebolehan dan keupayaan beliau sebagai ketua yang sangat mementingkan visi dan misi. Transformasi yang dibawa oleh pengetua wanita ini sewajarnya dijadikan sebagai sumber inspirasi untuk golongan pendidik wanita yang mempunyai potensi untuk diberikan amanah sebagai guru besar mahupun sebagai pengetua sekolah.

Sesungguhnya "tangan yang menghayun buaian itu mampu menggoncangkan dunia”

\section{Rujukan}

Abd Ghani, Aziah dan Tan, (2008). Kesan Pincang Laku Kepimpinan Pengetua Terhadap Guru: Universiti Sains Malaysia

Abdullah Ibrahim (2004). Kepimpinan Pendidikan Berkesan. Jurnal Akademik (2003/2004).14.92-96.

Acheson dan Smith, (1996). Kepengetuaan, Kepimpinan, Tugas dan Hubungannya dengan Falsafah Pendidikan-Satu Penjelasan dalam Musa Sulaiman (2004). Jurnal Akademik(2000/2001). 12.7585.

Andek Masnah Andek Kelawa (1999). Kepimpinan Wanita Dalam Islam: Kedudukannya Dalam Syariah.Bangi:Universiti Kebangsaan Malaysia. 
Aaltio-Marjosola I \& Takala T. (2000). Charismatic Leadership, Manipulation and the Complexity of Organizational Life. The Journal of Workplace Learning, Vol.12, Issue 4,2000, 146-159.

Ab.Aziz Yusof (2003). Pengurus dan Gelagat Organisasi Abad ke 21.Prentice Hall,Petaling Jaya,Selangor.

Akar.B and Mouchantaf. M. (2013). Social in Justice of Women as School Principals in Lebanon. In Bogotch,I. and Shields.C (eds), International Handbook of Social in Justice and Educational Leadersip, 2, Dordrecht: Springer.

Ayob Jantan. (2005). Pengetua sekolah yang efektif.Siri Pengurusan Sekolah. Bentong PTS Profesional Publishing Sdn.Bhd.

Collard, John L, (2001). Leadership and Gender: An Australian perspective. Educational Management and Administration 29 (3): 343-55.

Creswell, J.W. (2009). Research Design: Qualitative, quantitative, and mix methods approaches $\left(3^{\text {rd }}\right.$ ed.) California,USA:Sage Publications.Inc.

Cuban, L. (1988). The managerial imperative and the practice of leadership in effective schools. New York: State University of New York Press.

Coates, J. (1987). Women, men and language. $2^{\text {nd }}$ Edition. London: Longman.I

Gan Pei Ling (2003). Hubungan Persepsi Guru Terhadap Tingkah Laku Kepimpinan Pengetua dengan Tahap Motivasi Guru di Daerah Kuala Pilah, Negeri Sembilan. Tesis Master Sc.Fakulti Pengajian Pendidikan, Universiti Putra Malaysia, Serdang.

Hayes,G.M. (2013). The power of women who leads. Oregon: Harvest House Publishers

Holmes, J. (1995). Women, men and politeness. London: Longman

Ibrahim Mamat. (1993). Kepimpinan Sekolah :Teori Untuk Praktis.Kuala Lumpur:Dewan Bahasa \& Pustaka.

Ibrahim, Ali. and Mahmoud, Sherin. (2016). Principals'communication styles and schools performance in A1 Ain government school, UAE. United Arab Emirates University: United Arab Emirates.

Ikemaoto, G, Taliaferro, L \& Adams, E. (2012). Playmakers: How Great Principals Build and Lead Great Teams of Teachers. New York: New Leaders Inc.

Kamal Ariffin Jaih (2003). Stail Kepemimpinan Pengetua dan Kepuasan Kerja di Sebuah Sekolah Menengah Kebangsaan (Agama) di Pahang. Kertas Projek. Fakulti Pendidikan, Universiti Malaya, Kuala Lumpur.

Khadijah Walad (1999). Kepimpinan Pengetua dan Motivasi Guru: Satu Kajian di Sekolah Menengah. Tesis Sarjana. Pusat Ilmu Pengajian Pendidikan, Universiti Sains Malaysia, Pulau Pinang.

Kochan, F. K, Spencer, W.A \& Matthews, J.G, (2000).Gender-based Perceptions of the Challenges, Changes and Essential Skills of the Principalship. Journal of School Leadership 10 (4):290-310.

Karima Merchant (2012). How Men and Women Differ: Gender Diffrences in Communication Styles, Influence Tactics and Leaderships Styles.Claremont Colleges.

Leithwood, K. Day, C.Sammons, P.Harris A, and Hopkins,D. (2006). Seven strong claims about successful school leadership. National College for leadership. Nottingham.

Lumby, J. and Azaola,C de Wet, A, Skervin,H, Walsh,A. and Williamson, A. (2010). Women school principals in South Africa: Leading the way. Southampton: University of Southampton.

Louis,K. and Miles,M.B. (1990). Improving the urban high school: What works and why. New York: Teacher College Press.

Lakooff, B. (1973). Language and women's place. Language in Society.

Lunenerg, F.C. (2010). The principal and the school: What do Principals do?. National Forum of Education Administration and Supervision. 27(4): 199-207.

Morojele,P., Chikoko,V. and Ngbobo, N. (2013). Do women have to "Grow Muscles" in order to successfully manage schools? Evidence from some South African female school principals. Anthropologists.

Naidoo, B. and Perumal, J. (2014). Female principals leading at disadvantaged schools in Johannesburg, South Africa. Education Management Administration and Leadership, 1-17. Sage.

Omardin Ashaari. (1999). Pengurusan sekolah: Suatu panduan lengkap (Edisi ke-3). Kuala Lumpur: Utusan Publications and Distributors Sdn Bhd.

Tshilidzi Netshitangani (2008). Gender differences in communication styles: The impact on the managerial work of a woman school principal. ANZCA08 Conference, Power and Place, Wellington. 
Malaysian Journal of Social Sciences and Humanities (MJSSH), Volume 5, Issue 2, (page 54 - 66), 2020

DOI: https://doi.org/10.47405/mjssh.v5i2.367

Team FME (2013). Effective Communications: Communication Skills.www.free-managementebooks.com

Wiersma, W (1995). Research method in education: An introduction $6^{\text {th }}$ edition. Massachusetts: Allyn and Bacon. 